\title{
IT\&C support for decision making in notary offices
}

\author{
George Schin (Corresponding author) \\ "Dunarea de Jos" University \\ Str. Domneasca. 47, Galati, Romania \\ E-mail: george.schin@mail.com \\ Margareta Racovita \\ "Dunarea de Jos" University \\ Str. Domneasca. 47, Galati, Romania \\ E-mail: marga_racovita@yahoo.com
}

Received: May 06, 2013 Accepted: May 18, 2013 DOI: 10.5296/jpag.v3i2.3769

\begin{abstract}
The aim of this paper is to determine the most efficient strategic alternative in the case of a notary office, by taking into account the expected values associated to different levels of supplementary services requests by its customers. The determination of expected monetary values associated to the strategic alternatives by means of WinQSB software confirms the hypotheses concerning the feasibility analysis results and the manager's ability to make the right decision from the financial point of view. Thus, the manager of the notary office will be able to make efficient decisions regarding the business development plan by using appropriate software tools, which deliver real time results in different simulation scenarios. Once the optimal decision is found, the notary office can seek to improve its business development strategy by taking into account more options and levels of supplementary services requests from the part of its customers.
\end{abstract}

Keywords: decision tree analysis, notary office, information technology, expected monetary value 


\section{Introduction}

The management decisions making process using the method of the decision tree are made in the decisional complex situations, in which random events that take place successively are involved. By means of this method, the multi-sequential decisional processes are described under the form of some diagrams in which the future events condition the decision, determining a set of values concerning the results of each considered decision alternative [10]. This method provides an extremely useful tool for making operative decisions, being successfully used in the case of a succession of decisions interconnected in time.

Financial and managerial decisions are often based on information that is dependent on a variety of rules, estimates and conventions. The availability of software applications that run different simulations on desktop computers allows more decision-makers to generate and use uncertainty data [8].

Because the consequences of each decision are not known with certainty, the choice of the most beneficial decision and its value is typically calculated based on the values of each possible result multiplied by the probability of that result. Thus, the standard presentation of decision tree analysis bases the decision on the expected monetary value (EMV) of the alternatives [6].

Decision tree models are the transition point from the structuring phase to the evaluation phase of the decision analysis process. The issues generated during the business assessment and the decision hierarchies are important for the foundation of the decision tree model [14]. Decision tree method application approach involves several stages: developing an understanding of the application model, selecting a data set on which discovery is to be performed, choosing the appropriate data mining tasks and deployment of the decision tree in the order to select the optimal decision [11]. The way in which a decision or planning problem is framed, or viewed, will determine the extent to which account is taken of the different uncertainties that may impinge on the problem [3].

Decision trees are a rapid and effective method of classifying data set entries, and can offer good decision support capabilities. A decision tree is a tree in which each non-leaf node denotes a test on an attribute of cases, each branch corresponds to an outcome of the test, and each leaf node denotes a class prediction [7].

Decision support systems can aid human cognitive deficiencies by integrating various sources of information, providing intelligent access to relevant knowledge, and aiding the process of structuring decisions. They are especially valuable in situations in which the amount of available information is prohibitive for the intuition of an unaided human decision maker and in which precision and optimality are of importance [4].

Calculating the expected monetary value of each possible decision path is a way to quantify each decision in monetary terms. Determining expected monetary value by using decision trees is a recommended tool and technique for quantitative risk analysis [13].

Business decision and applications are described by normal comprehension of the problems to make the concepts approachable. Each business decision and application can be solved by 
several analytical activities called processing steps, which involve several characteristics to accomplish the analysis [12].

The solution of a decision problem involves observation, processing, and modelling of statistical data in order to quantify the uncertainty. Better data measurement and estimation of uncertainty add more consistency to the solution of a decision problem [9]. Multi-attribute decision models could be effectively utilized to solve the decision situations which can be encountered [5].

The structure of this paper is as follows. After this introductory section, the next one introduces the framework related to the analysis of the different alternative decisional options that a notary office could take into account. The third section presents the results of the expected monetary values associated to each decisional tree branch, after the implementation of the forecasted scenario using WinQSB software. The last section emphasizes the benefits of information and communication technology tools in decision making process and outlines future research agenda.

\section{Modeling the decision making processes in a notary office by means of the decision tree method}

The decision tree method is applied to the highly complex decisional situations in which there are involved random events that take place successively. It leads to the description of the multi-sequential decisional processes under the form of diagrams in which the future events condition the decision, determining a set of values regarding the results of each decisional alternative. This method provides the deciders within the notary office an extremely useful tool for making decisions, being successfully used in a decision succession that is interconnected in time.

This approach starts from the idea that the manager of a notary office considers that he can't handle the higher and higher request of the clients' services and analyses three decisional alternatives that may lead to the solution of the clients' requests:

- (AD1): the rent of an additional office and the hire of specialized personnel (two employees);

- (AD2): the rent of two additional offices and the hire of specialized personnel (four employees);

- (AD3): the outsourcing of the additional notary service requests towards other notary offices.

The notary office's manager assigns the financial department the task to carry out a feasibility analysis concerning the predicted profits or losses according to different levels of the notary service requests $(60,80$ and 100 additional requests). (figure no.1) 


\begin{tabular}{|c|c|c|c|}
\hline Decisional alternative & $\mathbf{6 0}$ requests & $\mathbf{8 0}$ requests & $\mathbf{1 0 0}$ requests \\
\hline AD1 & -38.000 & 164.000 & 325.000 \\
\hline AD2 & -114.000 & 128.000 & 548.000 \\
\hline AD3 & 20.000 & 40.000 & 60.000 \\
\hline
\end{tabular}

Figure no. 1 - Decisional alternatives

The feasibility analysis predicts losses in case the notary office rents some additional offices and hires new personnel, under the conditions of a low demand of only 60 additional services. The decision of outsourcing the analysis to other notary offices doesn't involve the risk of financial losses, but the predicted profits are placed much under the limit of the other two decisional alternatives.

As the notary office's manager thinks that the most likely event is represented by the level of 80 additional notary service requests, we will provide this event the ' 1 ' importance coefficient. In the same time, the notary office's manager considers that the probability of the other two events (60 or 100 additional notary service requests) is three times lower, thus we will provide them the ' $1 / 3$ ' importance coefficient. The determination of the three events' probability to happen involves a standard process: (figure no. 2)

\begin{tabular}{|c|c|c|c|}
\hline Event & Weight & Standardization & Probability \\
\hline $\begin{array}{c}\text { 60 aditional requests of notary } \\
\text { services }\end{array}$ & $1 / 3$ & $(1 / 3) /(5 / 3)=0,2$ & $\mathbf{0 , 2}$ \\
\hline $\begin{array}{c}80 \text { aditional requests of notary } \\
\text { services }\end{array}$ & $3 / 3$ & $(3 / 3) /(5 / 3)=0,2$ & $\mathbf{0 , 6}$ \\
\hline $\begin{array}{c}100 \text { aditional requests of notary } \\
\text { services }\end{array}$ & $1 / 3$ & $(1 / 3) /(5 / 3)=0,2$ & $\mathbf{0 , 2}$ \\
\hline Total & $\mathbf{5 / 3}$ & - & $\mathbf{1}$ \\
\hline
\end{tabular}

Figure 2 - Probabilities related to different levels of additional notary services requests

The process of choosing the appropriate decisional alternative is represented in a decision tree like chart made of nodes (decision and uncertain results type) and branches (nature condition type and decision variants type). In this context, the initial node will generate three main branches (corresponding to the three alternatives taken into consideration by the notary 


\section{Macrothink}

Journal of Public Administration and Governance

office's manager) and from each terminal node of these three branches there will converge three branches

specific to the three levels of the additional notary service requests whom the probabilities calculated in advance will be assigned to.

We will calculate the expected average revenue (EMV) in the nodes 2,3 and 4 according to the mathematic formula in order to determine the appropriate decision alternative:

$$
\mathrm{EMV}=\sum p_{i} x V_{e}
$$

EMV - the expected monetary value in the node ' $\mathrm{l}$ '

$\mathrm{P}_{\mathrm{i}}$ - the probability associated to a branch of the decision tree which has the starting point in node ' $\mathrm{i}$ '

$\mathrm{V}_{\mathrm{e}}-$ the profit or the loss value estimated in the final nodes.

The determination of the expected average revenue values associated to the nodes 2, 3 and 4 is based on the 'roll-back' procedure which presupposes the selection of the right decision at the level of the last decision point, according to the criteria of the maximum mathematic expectation.

The selection of the appropriate decision variant continues on the next previous level up to the initial node level.

$$
\begin{aligned}
& \mathrm{EMV}_{2}=0,2 \times(-38.000)+0,6 \times 164.000+0,2 \times 325.000=155.800 \mathrm{RON} \\
& \mathrm{EMV}_{3}=0,2 \times(-114.000)+0,6 \times 128.000+0,2 \times 548.000=166.600 \mathrm{RON} \\
& \mathrm{EMV}_{4}=0,2 \times 20.000+0,6 \times 40.000+0,2 \times 60.000=40.000 \mathrm{RON}
\end{aligned}
$$

The maximum value between the expected average revenues in the nodes 2,3 and $4\left(\mathrm{EMV}_{3}=\right.$ 166.600 RON) will be chosen in the initial node (1). This leads to the fact that the decision of renting two additional offices and employing specialized personnel (four persons) is very efficient from the predicted income point of view.

\section{Decisional problem solving by means of WinQSB software}

The solution of this problem concerning the modeling of the decision making processes by the manager of a notary office by means of the decision tree method, using the WinQSB software, involves the access of the Decision Analysis menu and then, the Decision Tree Analysis module.

The entry data base will contain the names of the 13 nodes, the type of each node (decision or uncertain result), the decision tree chart, taking into account the interdependencies between nodes and branches, the profit values, respectively the predicted losses corresponding to each decision alternative, as well as the occurrence probabilities of the three alternatives. 


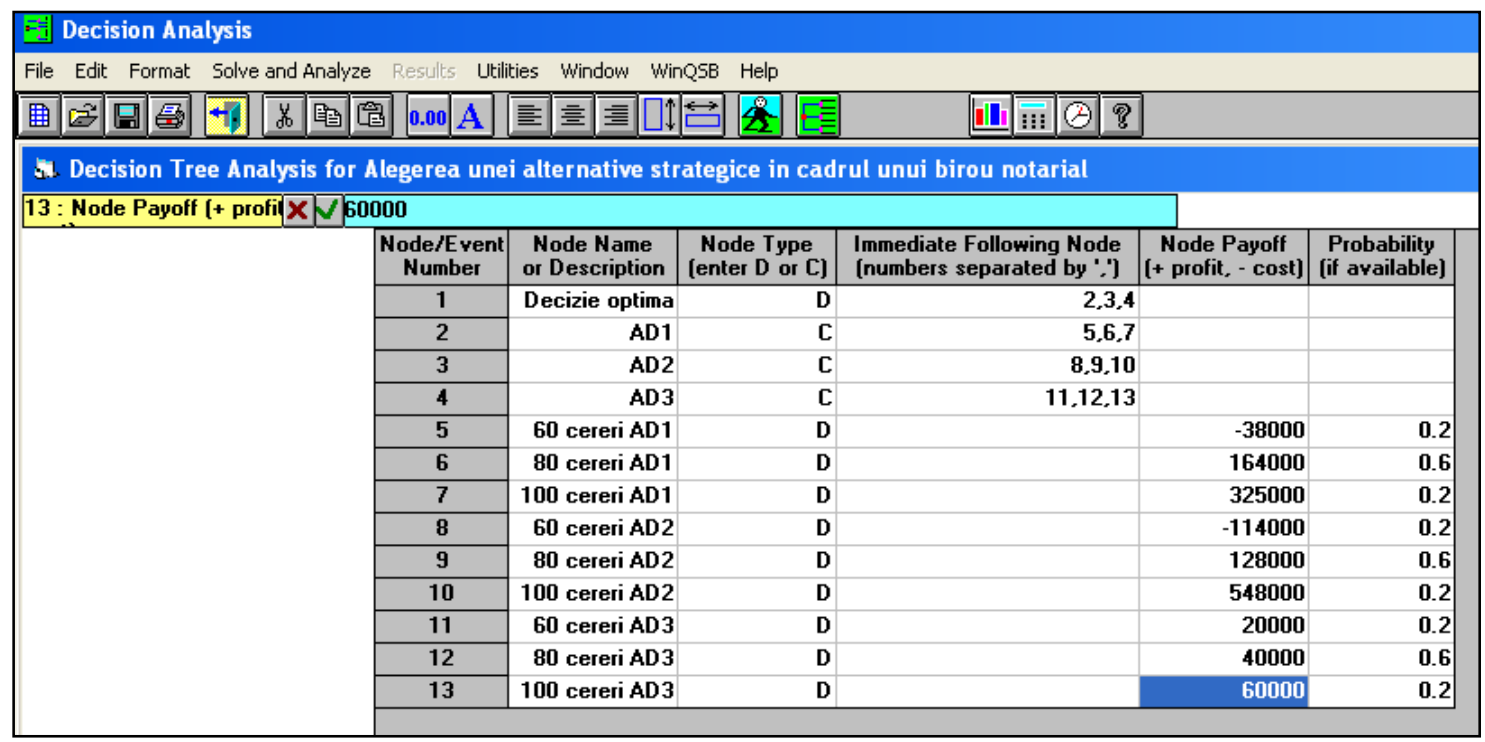

Figure 3 - The entry data of the decision problem within the notary office in the Decision

\section{Analysis}

The conversational system solution with the WinQSB software involves the determination of the expected average revenue in the nodes 2,3 and 4 by means of the function Solve the problem, considering the fact that the intermediary decisions are conditioned by the estimated results of the final decisions. The choice of the appropriate solution with the decision tree method and the values of the expected average revenues in the nodes where the branches converge, that have the three decision alternatives represented are illustrated in figure below.

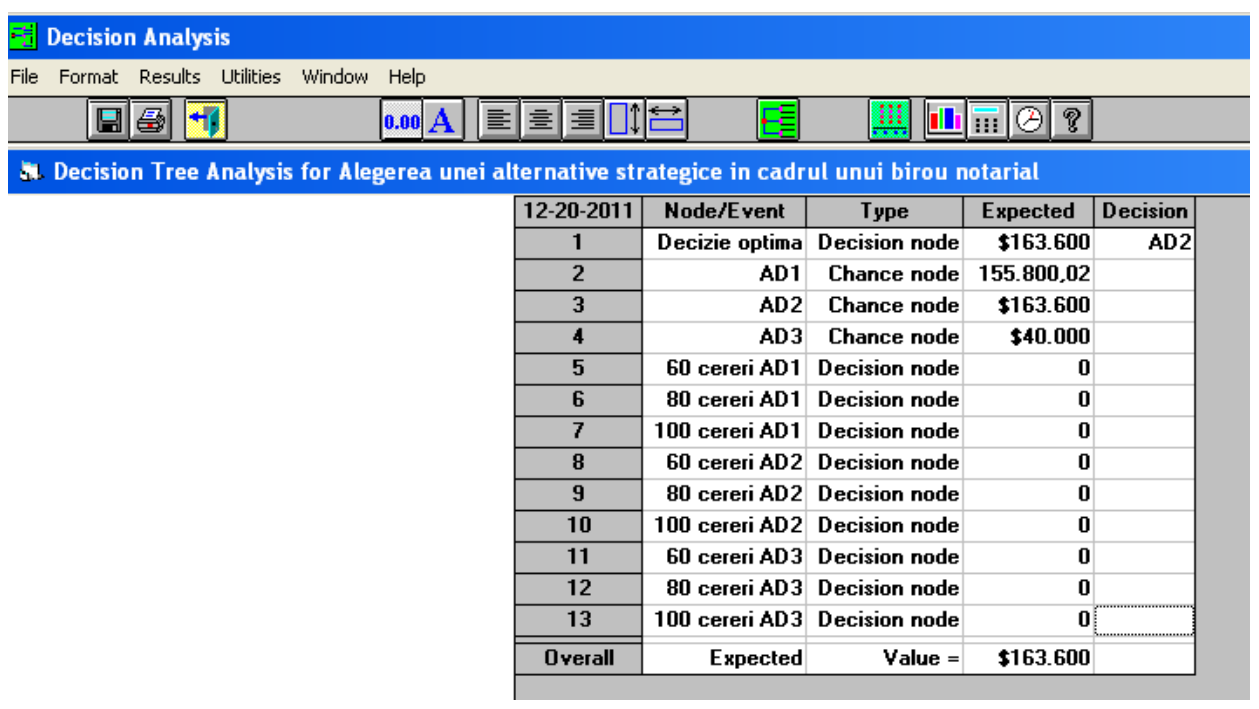

Figure 4 - The results of the decision problem within the notary office provided by the

Decision Analysis module of the WinQSB software 
In order to visualize the decision tree built by WinQSB computer application, the notary office manager can access the function Show Decision Tree Graph within the Results menu of the Decision Analysis module.

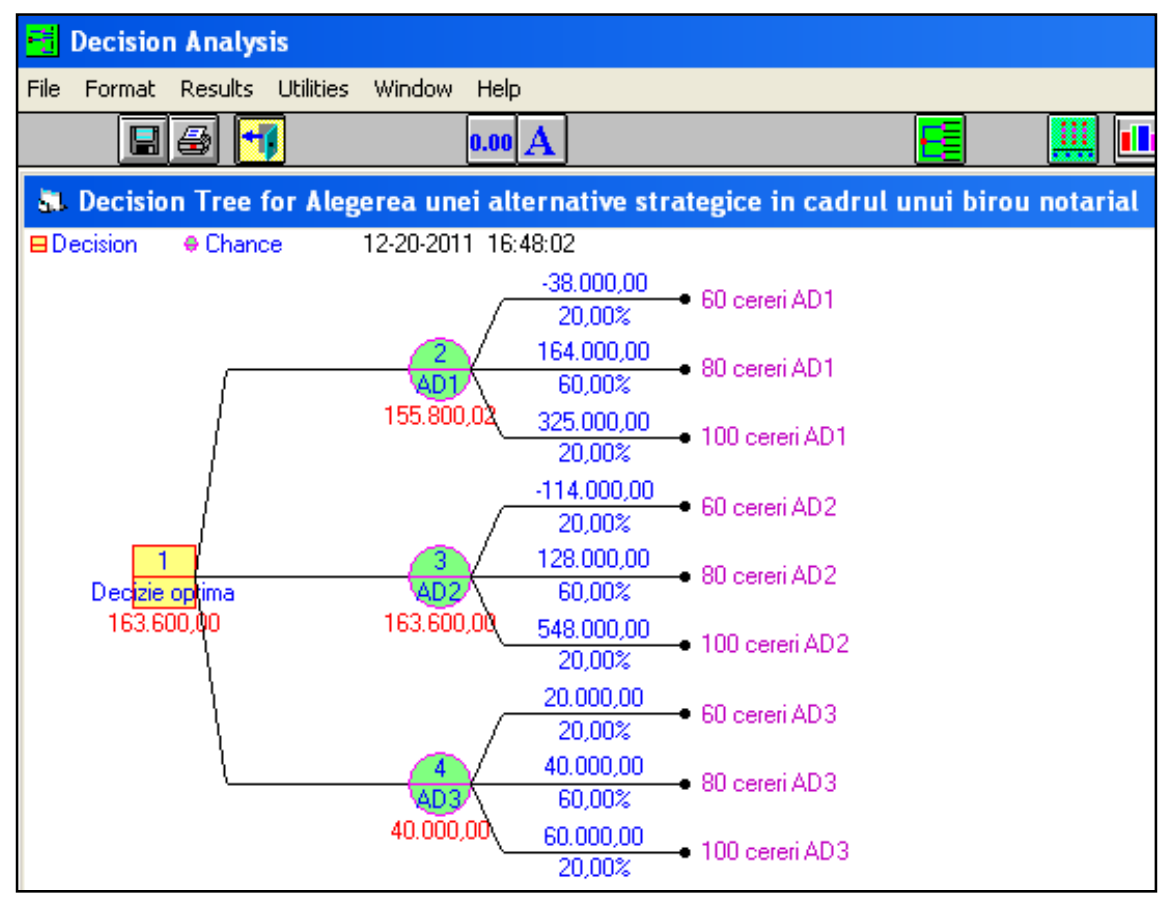

Figure 5 - The decision tree simulated by means of the function Show Decision Tree Graph implemented within WinQSB computer application

According to the development of the decision processes, the alternatives taken into consideration by the notary office's manager can become reality, confirming the initial hypothesis regarding the results of the feasibility analysis and the manager's ability to make the right decision from a financial point of view.

\section{Conclusions and research implications}

The article reveals the advantages of the decision making process simulation, facilitated by the interconnections between the functions provided by the WinQSB software. Once the optimal decision is found, the notary office manager can seek to improve that solution by finding ways to relax binding constraints. This conceptual framework can be customized to any type of business activity, revealing the interdependences between its variables and constraints and emphasizing the value of the decision tree approach in the formulation of a business problem.

The efficient mix of the tools provided by the WinQSB software allows a better understanding of the decision making process in a way that is in line with the reality faced by the managers, involving a high degree of uncertainty, probabilities definition, major resource implications and long-term consequences. Thus, the managers have the opportunity to analyze in a comparative manner the decisional alternatives, in terms of risk and probable value. WinQSB software provides the expected monetary values in terms of relative 
investment costs, anticipated payoffs, and uncertainties and combine them into a single numerical value.

Thus, the notary office managers must understand how the new information and communication technologies provides an effective support for decision making process in the context of different scenarios, which involves specific probabilities and risks.

The findings of this study highlight decisional process stages, in order to better understand the degree to which different decisional alternatives can be customized to specific contexts.

Being aware of the limited explanation power of the WinQSB software application to the notary office dynamics, we intend to further design of a decisions-support system, focused on goal seek and optimization patterns analysis, defining target variables according to certain constraints and searching the optimal values by means of what-if analysis.

\section{References:}

[1] Y.L. Chang, K. Desai, WinQSB: Decision Support Software, Pearson Education, New York, 2003

[2] B. De Ville, Decision Trees for Business Intelligence and Data Mining: Using SAS Enterprise Miner, SAS Publishing, 2006

[3] M.J. Druzdzel, R. Flynn, Decision Support Systems, Encyclopedia of Library and Information Science, Second Edition, Allen Kent (ed.), New York, 2002

[4] F.G. Filip, A Decision-Making Perspective for Designing and Building Information Systems, International Journal of Computers Communications \& Control, 7(2), 264-272, 2012

[5] D.T. Hullet, Decision Tree Analysis for the Risk Averse Organization, Proceedings of PMI EMEA Congress in Madrid, Spain, May 9, 2006

[6] S. Lee, Using data envelopment analysis and decision trees for efficiency analysis and recommendation of B2C controls, Decision Support Systems, 49, 486-497, 2010

[7] L. S. Mahoney, P. B. Roush, D. Bandy, An investigation of the effects of decisional guidance and cognitive ability on decision making involving uncertainty data, Information and Organization, 13, 85-110, 2003

[8] I. Parpucea, B. Parv, T. Socaciu, Modeling Uncertainty in a Decision Problem by Externalizing Information, International Journal of Computers Communications \& Control, 6(2), 328-336, 2011

[9] C. Ratiu-Suciu, Modeling and Simulations of Economic Processes, Ed. Economica, Bucuresti, 2004

[10] L. Rokach, O. Maimon, Data Mining with Decision Trees, World Scientific Publishing Co., Singapore, 2008

[11] J.L. Seng, T.C. Chen, An analytic approach to select data mining for business decision, Expert Systems with Applications, 37, 8042-8057, 2010

[12] R. Sharma, Using a Decision Trees Example in Project Risk Management to Calculate Expected Monetary Value", http://www.brighthub.com, accessed on 14th March 2011 
[13] D. Skinner, Introduction to Decision Analysis, Third Edition, Probabilistic Publishing, Gainsville, 2003 